\title{
Glans-urethral meatus-shaft score and penile parameters as preoperative assessment tools for hypospadias surgery outcome
}

\author{
Ahmed Shoukry, Ahmed Abbas, Mohamed Abdelwahab, Waleed Ghoneima, Ahmed Shouman,
} Mohamed El Ghoneimy, Hani Morsi, Hesham Badawy, Mohamed Eissa and Waseem Aboulela* (1)

\begin{abstract}
Background: Our prospective study aims to assess if penile parameters and GMS score can predict the postoperative outcome of patients with hypospadias repaired with the TIP technique.

Methods: This prospective study included patients ( 6 months-11 years old) with coronal, distal or mid penile hypospadias who underwent Tubularized incised plate (TIP) urethroplasty technique from 2015 to 2017. All patients were assessed preoperatively using GMS score. GMS score included a scale for each component, with the more unfavorable characteristics assigned higher scores. Penile length, urethral plate length, and penoscrotal length were measured using a ruler. Glans width was measured by using a caliper ruler. Demographics and complications were assessed within 3 months of the procedure.

Results: There was a statistically significant difference between complicated and non-complicated patients regarding GMS score, glans width, penoscrotal length, penile length, and urethral plate length/penile length ratio. According to the ROC curve, the cutoff values for GMS score, glans width and penoscrotal length were $6,14 \mathrm{~mm}$ and $5 \mathrm{~cm}$, respectively. The area under the ROC curve for penile length and for urethral plate/penile length ratio was poor and so we could not get a specific cutoff value for either parameters. According to Stepwise logistic regression, the GMS score was the only significant independent parameter while controlling all the other factors. Any increase in the GMS score by one unit would increase the risk of complications 3 times.

Conclusion: GMS score and penile parameters are good predictors and complete each other in preoperative assessment for hypospadias patients. Patients with a high GMS score (above 6) have a higher risk of complication and patients with a Glans width of $14 \mathrm{~mm}$ or more and a penoscrotal length of $5 \mathrm{~cm}$ or more are associated with less risk of complication.
\end{abstract}

Keywords: Penile length, Glans width, Penoscrotal length, GMS score, Urethral plate, Penile length ratio, Hypospadias

\section{Background}

Hypospadias is among the foremost common congenital anomalies of the genito-urinary tract, and its surgical repair remains a constructive challenge [1-3]. While

*Correspondence: Waseem_aboul_ela@yahoo.com

Kasr Al Ainy, Cairo University, Cairo, Egypt modern repair goals are to achieve excellent hypospadias repair outcomes, it is not that simple. Hypospadias is a broad-spectrum anomaly. It is well known that several factors affect the assessment and postoperative outcome. Therefore, an objective tool should adequately assess the entire hypospadias complex rather than just depending on a single factor as the meatal location $[1,4,5]$. 
Although several validated scores now exist for assessing cosmetic outcomes following hypospadias repairs, such as Pediatric Penile Perception Score (PPPS), Hypospadias Objective Scoring Evaluation (HOSE), and Hypospadias Objective Penile Evaluation (HOPE), the need for standardized hypospadias reporting remains for proper preoperative evaluation [6-8].

The Glans-Urethral Meatus-Shaft (GMS) score is a concise and reproducible way to describe hypospadias severity preoperatively to predict the surgery outcome $[1$, 4].

Nonetheless, the GMS score is a subjective tool and does not meet all the penile biometric criteria. On the other hand, one of the most critical factors that affect the success rate is the type of repair itself. Many techniques offer an excellent surgical outcome, including the Tubularized Incised Plate (TIP) $[9,10]$.

Our prospective study aims to assess if penile parameters and GMS score can predict the postoperative outcome of patients with hypospadias repaired with the TIP technique.

\section{Methods}

This study was conducted between January 2015 and March 2017. We designed a prospective protocol at our institution to apply the GMS score and to measure specific penile biometric parameters for children presenting with hypospadias. The study included 70 children presenting with distal or mid penile hypospadias with no prior history of surgical correction. Children presenting with proximal hypospadias were excluded. We do not give preoperative androgen stimulation to our patients. GMS score was assigned by at least 3 of 4 surgeons. In the GMS score, each of the three components is numerically evaluated on a scale from 1 to 4 . G for glans size/ urethral plate quality, $\mathrm{M}$ for meatal location, and $\mathrm{S}$ for the degree of shaft curvature. The more unfavorable the parameter is, the higher it is scored [4] (Table 1).

In case of discrepancy in their opinions, the higher scores were chosen. Penile measurements included, Penile length (PL), which is the distance between the symphysis pubis and tip of the penis, urethral plate length (UPL), which is the distance between the meatal opening and tip of the penis, penoscrotal length (PSL) which is the distance between the tip of the penis and base of the scrotum and glans width (GW) (Fig. 1). UPL/PL ratio was also calculated for each patient. All measurements were measured by using a ruler and a caliper ruler for the glans width.

Tubularized incised plate (TIP) urethroplasty technique was assigned to be performed for all patients included in this study unless the surgeon decides otherwise intraoperatively due to technical difficulties encountered that

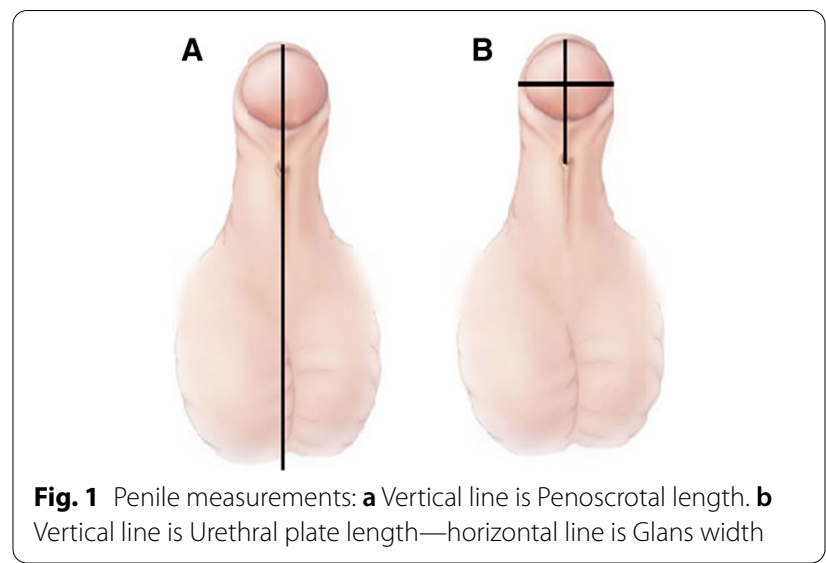

might affect surgical success. All chordee was released by penile skin degloving and did not require further management. The technique was standardized, and the suture material (6/0 PDS), 8-10 Fr catheter was left for one week, and three senior surgeons performed all surgeries. Demographics and complications (urethrocutaneous fistula, meatal stenosis, glans dehiscence, phimosis, recurrent chordee, and stricture) were assessed within three months of the procedure.

\subsection{Statistical methods}

Preceded data were entered into the computer using the statistical package of the social science software program, version21 (SPSS), to be statistically analyzed. Data were summarized using mean and SD for quantitative variables, while numbers and percentages were used for a qualitative variable.

Comparison between quantitative variables was made using independent $\mathrm{T}$ test for normally distributed variables and nonparametric Mann-Whitney test variables, which were not normally distributed. Comparison between qualitative variables was made using the chisquare test. ROC (receiver operator characteristic curve) was used to determine individual variables' best cutoff and validity. Binary logistic regression was done to explore the significant predictors of complication among significant variables in the univariate analysis. A $P$ value less than 0.05 was considered statistically significant. Written consent was taken from all patients included in the study.

\section{Results}

Seventy patients with distal and mid penile hypospadias were included in our prospective study. Four patients were excluded from our study as the surgeon did not perform TIP repair. The repair type was changed intraoperatively by the surgeons, and they did not find the TIP a 
suitable technique for repair after penile skin degloving. Surgeons preferred patients with good urethral plates and mild chordee. All patients came for a first visit follow-up at one week and later at three months, except for complicated patients, followed up more frequently. Five patients came for their follow-up to remove the catheter at one week and missed their follow-up at three months. All five patients had successful repairs at one week. We report the results for 61 patients who met our inclusion criteria. The age of patients ranged from 1 to 11 years. All children did not have any previous surgical repair.

There was no statistically significant difference in age between complicated and non-complicated cases. The total success rate was $60.6 \%$. Postoperative complications occurred in 24 patients (39.4\%); 15 patients $(24.60 \%)$ had a postoperative fistula; four patients $(6.6 \%)$ had meatal stenosis, four patients (6.6\%) had failed hypospadias repair, and one patient (1.6\%) had recurrent chordee (Table 2). All fistulae were closed successfully after six months. Meatal stenosis was reported in $6.60 \%$ of the patients, to whom the parents performed regular meatal dilatation with the tip of a mercury thermometer twice per day. After two weeks, patients did not need further dilatation. Failed hypospadias repair was reported in four patients $(6.60 \%)$, and they were all scheduled for redo surgeries. One patient $(1.60 \%)$ presented with a chor- complicated and non-complicated patients regarding GMS score, glans width, penile length, penoscrotal length, and urethral plate length/penile length ratio, as shown in Table 3.

Stepwise logistic regression was performed to assess the impact of different factors on the likelihood that patients would report complications. The model contained six independent variables; GMS score, UPL $(\mathrm{cm})$, GW $(\mathrm{cm})$, PSL $(\mathrm{cm})$, PL $(\mathrm{cm}) \&$ UP/PL ratio. While controlling all the factors in the model, only the GMS score was significant. The odds ratio was 3.23; any increase in GMS score by one unit; the patient would have three times the risk to develop a complication (Tables 4, 5).

Table 6 illustrates that patients with a high GMS score (above 6) have a higher risk of complication and that patients with a Glans width of $14 \mathrm{~mm}$ or more and a penoscrotal length of $5 \mathrm{~cm}$ or more are associated with less risk of complication (Figs. 2, 3, 4).

\section{Discussion}

Proper stratification and grading of risk factors affecting the surgical outcome of hypospadias repair remain a point of interest among all surgeons. Up till now, there is no universally standardized grading system for the hypospadias complex [4]. Efforts are ongoing to develop a reliable prognostic model which allows wise preoperative planning and

Table 1 GMS score

\begin{tabular}{llll}
\hline G & Glans score & Meatus Score & Shaft Score \\
\hline 1 & $\begin{array}{c}\text { Glans good size/healthy urethral plate, } \\
\text { deeply grooved } \\
\text { Glans adequate size/adequate urethral } \\
\text { plate, grooved } \\
\text { Glans small size/narrow urethral plate, } \\
\text { some fibrosis }\end{array}$ & Coronal sulcus & Mid or distal shaft \\
3 & $\begin{array}{c}\text { Glans very small size/indistinct urethral } \\
\text { plate, very narrow or flat }\end{array}$ & Proximal shaft, penoscrotal & Mild $\left(<30^{\circ}\right)$ chordee \\
4 & Moderate $\left(30^{\circ}-60^{\circ}\right)$ chordee \\
\hline
\end{tabular}

dee of more than 30 degrees postoperatively, to which repair was done after six months with dorsal plication. There was a statistically significant difference between parental counseling. From that standpoint, plenty of studies tried to assess penile biometric parameters either separately or combined for a proper description of hypospadias

Table 2 Complications

\begin{tabular}{llr}
\hline & N & \% \\
\hline No complication & 37 & 60.70 \\
Fistula & 15 & 24.60 \\
Failed repair & 4 & 6.60 \\
Stenosis & 4 & 6.60 \\
Recurrent chordee & 1 & 1.60 \\
\hline
\end{tabular}




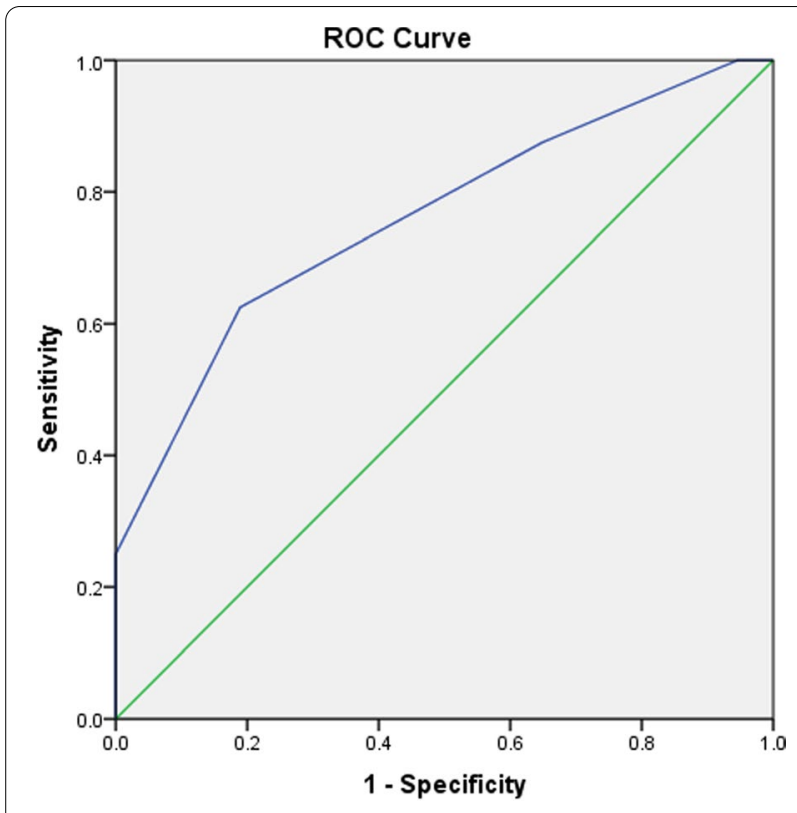

Diagonal segments are produced by ties.

Fig. 2 GMS ROC curve severity, but in the light of the absence of standardized grading, controversy remains. Bush NC and colleagues conducted their study to evaluate the correlation of glans size and urethroplasty complications after hypospadias repair. They found that complication rates were higher in those with glans size less than $14 \mathrm{~mm}$ (20/81, i.e., 25\%) versus (41/409 i.e., $10 \%)$ in patients with glans more than $14 \mathrm{~mm}$, confirming our results. They also demonstrated that each $1 \mathrm{~mm}$ decrease in the glans' size increased the odds of urethrocutaneous fistula and vice versa [11]. The study included primary and reoperation, distal, and proximal cases and did not standardize all patients' surgical techniques. Along the same lines, Huang et al. investigated the glans and urethral plate width as risk factors for postoperative complications in hypospadias repair. They found higher rates of complications in patients with glans width less than $13.5 \mathrm{~mm}(12 / 50$, i.e., $24 \%)$ versus (96/75 i.e., $8 \%)$ in patients with glans width more than $13.5 \mathrm{~mm}$. Similarly, they found that urethral plate width less than $3.75 \mathrm{~mm}$ was significantly associated with higher complication rates. $12 / 47(25 \%)$ in patients whose urethral plate width less than $3.75 \mathrm{~mm}$ compared to $6 / 78(7.7 \%)$ in those with urethral plate width more than $3.75 \mathrm{~mm}$ [12]. In contrast,

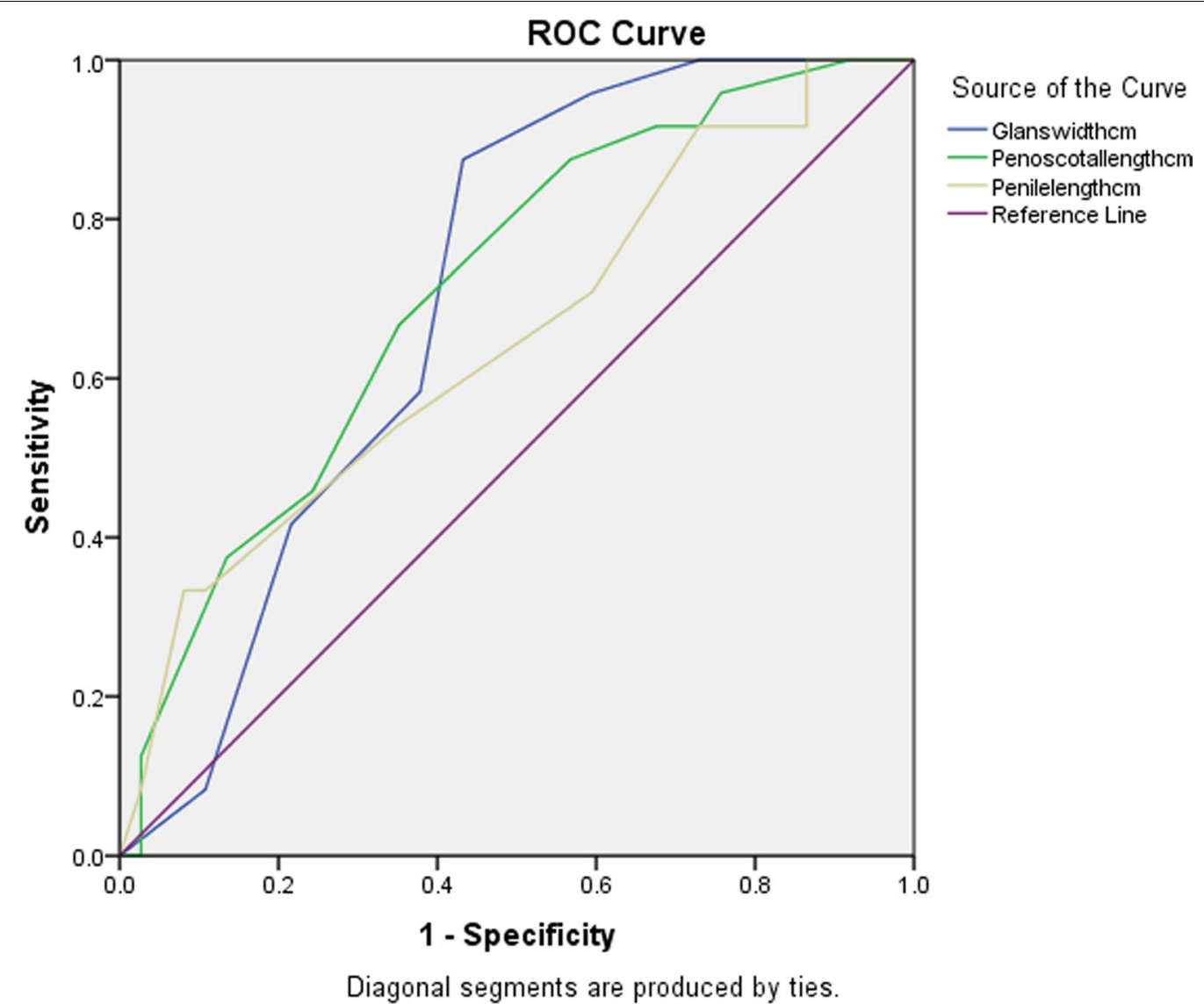

Fig. 3 ROC curve of glans width, penoscrotal length, and penile length 


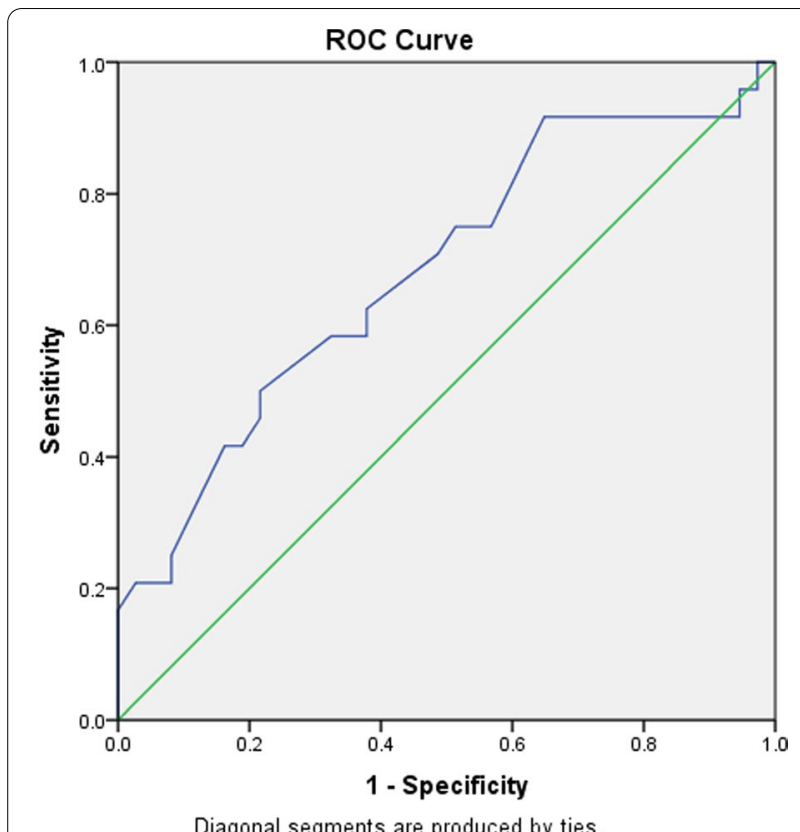

Diagonal segments are produced by ties.

Fig. 4 ROC curve of urethral plate/penile length ratio
Faasse et al. concluded that the width of the glans penis was not an independent risk factor for glandular complication and urethroplasty after hypospadias repair. Their study included 159 patients, 140 underwent single-stage repair while 19 patients had a two-stage repair. However, they did not standardize their surgical technique in all patients. Eighty-four patients (53\%) had a preoperative local testosterone cream treatment, and had significantly wider glans $(15.5 \mathrm{~mm})$ compared to the other 75 patients who did not receive androgen stimulation $(14 \mathrm{~mm})$ [13]. The impact of androgen stimulation on surgery is still controversial [14]. Moreover, the second group with relatively smaller glans had a median width of $14 \mathrm{~mm}$, which is accepted in other studies as a cutoff value for a wide glans penis. This supports that we should all use the same terminology in describing the hypospadias complex by developing a standard prognostic model with clear cutoff values.

Although the GMS score provides a more detailed way to evaluate the severity of hypospadias properly, the score itself remains a subjective tool that depends on the surgeon's point of view.

In 2013 Merriman and colleagues handled the GMS score's subjective aspect by judging the interobserver reliability in assigning scores of each component. Also, they assessed the GMS score correlation with postoperative

Table 3 Mean values of GMS score and penile parameters in complicated and non-complicated cases

\begin{tabular}{|c|c|c|c|c|c|c|c|}
\hline & \multicolumn{2}{|c|}{ All patients } & \multicolumn{2}{|c|}{ Non-complicated 37 patients } & \multicolumn{2}{|c|}{ Complicated 24 patients } & \multirow[t]{2}{*}{$p$ value } \\
\hline & Mean & SD & Mean & SD & Mean & SD & \\
\hline Age (years) & 3.29 & 2.60 & 3.5 & 2.9 & 2.9 & 2.1 & 0.346 \\
\hline GMS score (3-12) & 6.16 & 1 & 5.8 & 0.8 & 6.8 & 1.0 & $<0.001^{*}$ \\
\hline $\begin{array}{l}\text { Urethral plate } \\
\text { length }(\mathrm{cm})\end{array}$ & 1.067 & 0.277 & 1.1 & 0.3 & 1.1 & 0.3 & 0.462 \\
\hline Glans width (cm) & 1.362 & 0.422 & 1.5 & 0.5 & 1.2 & 0.1 & $0.007^{*}$ \\
\hline $\begin{array}{l}\text { Penoscrotal length } \\
(\mathrm{cm})\end{array}$ & 8.024 & 1.721 & 8.5 & 1.9 & 7.4 & 1.1 & $0.013^{*}$ \\
\hline Penile length (cm) & 4.095 & 1.069 & 4.3 & 1.2 & 3.8 & 0.8 & $0.041^{*}$ \\
\hline $\begin{array}{l}\text { Urethral plate/ } \\
\text { PENILE length** }\end{array}$ & 27.1 & 8 & 24.96 & \pm 6.45 & 30.32 & \pm 9.11 & $0.017^{*}$ \\
\hline
\end{tabular}

* Significant $p$ Value

**Ratio

GMS-Glans-Urethral Meatus-Shaft

Table 4 Stepwise logistic regression table

\begin{tabular}{|c|c|c|c|c|c|}
\hline & \multirow[t]{2}{*}{ B } & \multirow[t]{2}{*}{$p$ value } & \multirow[t]{2}{*}{ Odd ratio } & \multicolumn{2}{|c|}{$95 \% \mathrm{Cl}$} \\
\hline & & & & Lower & Upper \\
\hline GMS score & 1.174 & 0.003 & 3.234 & 1.478 & 7.075 \\
\hline Glans width (cm) & -2.928 & 0.113 & 0.053 & 0.001 & 2.006 \\
\hline Penoscrotal length (cm) & -0.548 & 0.085 & 0.578 & 0.31 & 1.078 \\
\hline Constant & 0.223 & 0.954 & 1.249 & & \\
\hline
\end{tabular}


Table 5 GMS Score for each patient

\begin{tabular}{|c|c|c|c|c|c|c|c|c|c|c|c|c|c|c|}
\hline$P$ & G & $M$ & $S$ & Score & $P$ & $\mathbf{G}$ & $M$ & $S$ & Score & $P$ & G & $M$ & $S$ & Score \\
\hline 1 & 2 & 2 & 2 & 6 & 25 & 2 & 2 & 2 & 6 & 49 & 1 & 3 & 1 & 49 \\
\hline 2 & 2 & 3 & 1 & 6 & 26 & 3 & 2 & 2 & 7 & 50 & 3 & 3 & 1 & 50 \\
\hline 3 & 2 & 2 & 1 & 5 & 27 & 1 & 2 & 2 & 5 & 51 & 2 & 2 & 2 & 51 \\
\hline 4 & 2 & 3 & 1 & 6 & 28 & 2 & 2 & 2 & 6 & 52 & 1 & 3 & 2 & 52 \\
\hline 5 & 2 & 2 & 2 & 6 & 29 & 2 & 3 & 2 & 7 & 53 & 1 & 3 & 1 & 53 \\
\hline 6 & 3 & 2 & 2 & 7 & 30 & 2 & 2 & 1 & 5 & 54 & 1 & 3 & 2 & 54 \\
\hline 7 & 2 & 2 & 1 & 5 & 31 & 2 & 2 & 2 & 6 & 55 & 1 & 2 & 2 & 55 \\
\hline 8 & 2 & 2 & 1 & 5 & 32 & 2 & 3 & 1 & 6 & 56 & 2 & 3 & 2 & 56 \\
\hline 9 & 2 & 3 & 2 & 7 & 33 & 2 & 2 & 1 & 5 & 57 & 1 & 3 & 2 & 57 \\
\hline 10 & 1 & 2 & 1 & 4 & 34 & 3 & 3 & 1 & 7 & 58 & 2 & 3 & 2 & 58 \\
\hline 11 & 2 & 2 & 1 & 5 & 35 & 2 & 2 & 2 & 6 & 59 & 3 & 3 & 1 & 59 \\
\hline 12 & 2 & 2 & 2 & 6 & 36 & 2 & 3 & 1 & 6 & 60 & 3 & 3 & 2 & 60 \\
\hline 13 & 3 & 3 & 2 & 8 & 37 & 2 & 2 & 2 & 6 & 61 & 2 & 3 & 2 & 61 \\
\hline 14 & 2 & 3 & 2 & 7 & 38 & 3 & 2 & 1 & 6 & & & & & \\
\hline 15 & 2 & 2 & 2 & 6 & 39 & 2 & 2 & 1 & 5 & & & & & \\
\hline 16 & 2 & 3 & 1 & 6 & 40 & 2 & 2 & 1 & 5 & & & & & \\
\hline 17 & 2 & 2 & 2 & 6 & 41 & 2 & 2 & 1 & 5 & & & & & \\
\hline 18 & 2 & 2 & 2 & 6 & 42 & 2 & 3 & 1 & 6 & & & & & \\
\hline 19 & 3 & 3 & 2 & 8 & 43 & 3 & 3 & 2 & 8 & & & & & \\
\hline 20 & 2 & 3 & 2 & 7 & 44 & 3 & 3 & 2 & 8 & & & & & \\
\hline 21 & 2 & 2 & 1 & 5 & 45 & 3 & 3 & 2 & 8 & & & & & \\
\hline 22 & 2 & 2 & 2 & 6 & 46 & 2 & 3 & 1 & 6 & & & & & \\
\hline 23 & 2 & 3 & 2 & 7 & 47 & 2 & 3 & 2 & 7 & & & & & \\
\hline 24 & 2 & 3 & 2 & 7 & 48 & 1 & 2 & 1 & 4 & & & & & \\
\hline
\end{tabular}

$\mathrm{P}=$ Patient number $\mathrm{G}=\mathrm{Glans} ; \mathrm{M}=$ Meatus $\mathrm{S}=$ Shaft

outcomes. The study included 85 patients; surgical techniques were not the same in all patients; in 51 patients, TIP repair was done, 19 had Thiersch-Duplay, GAP was done in 6 patients, MAGPI in 4 two-stage repairs in 4 patients [4]. They concluded that the GMS score has high inter-observer reliability. It offers a simple, brief, and reproducible way to describe the hypospadias complex and correlates well with the risk of surgical complications. They also stated that the GMS score could be considered a good starting point for more refinements and better evaluation. The complication rate was $5.6 \%$ for patients with a GMS score of 6 or less but was $25.0 \%$ for patients with a GMA score greater than 6 .

In 2015 Arlen et al. continued on the same track. They concluded that there is a significant relationship between the total GMS score and the presence of postoperative complications. Every unit increase in GMS scores increased the odds of postoperative complications by 1.44 times. A significant limitation to their study was that

Table 6 (AUC) Area under the ROC curve for GMS score and penile parameters

\begin{tabular}{|c|c|c|c|c|c|c|c|}
\hline $\begin{array}{l}\text { Test result } \\
\text { variable(s) }\end{array}$ & AUC (\%) & $P$ value & $95 \%$ interval & Confidence & Cutoff value & Sensitivity (\%) & Specificity (\%) \\
\hline GMS score & 76 & $0.001^{*}$ & 0.633 & 0.888 & 6 & 62.5 & 81.1 \\
\hline Glans width (cm) & 70.30 & $0.008^{*}$ & 0.574 & 0.832 & $14 \mathrm{~mm}$ & 87.5 & 56.8 \\
\hline $\begin{array}{l}\text { Penoscrotal length } \\
(\mathrm{cm})\end{array}$ & 71.10 & $0.006^{*}$ & 0.581 & 0.841 & $5 \mathrm{~cm}$ & 87.5 & 43.2 \\
\hline Penile length $(\mathrm{cm})$ & 64.90 & $0.051^{*}$ & 0.506 & 0.791 & & & \\
\hline $\begin{array}{l}\text { Urethral plate/ } \\
\text { penile length } \\
\text { ratio }\end{array}$ & 68.20 & $0.017^{*}$ & 0.542 & 0.822 & & & \\
\hline
\end{tabular}


the surgeon preference influenced the type of repair [1]. In our study, four patients were excluded from the study, because the surgeon decided that the TIP repair is not suitable (Tables 1, 2, 4, 5).

Da Silva EA and colleagues tried to investigate the influence of penile biometric characteristics on the surgical outcome of TIP repair of hypospadias. The preoperative assessment focused on glans shape, urethral plate length and width, prepuce vascularization, and penile size. All the patients had anterior hypospadias, all of them were primary, and none of them received androgen stimulation before surgery. They concluded that the glans shape, UP width, UP length, prepuce vascularization, and penile size have no significant effect on TIP repair's complication rate in distal hypospadias [15].

Our current study investigated the correlation of GMS score and other penile biometric parameters with surgical outcomes. We tried to avoid the limitations found in the other studies by decreasing the variables that can affect the surgical outcome. We agree with others that the total GMS score, glans width, penoscrotal length, and penile length can significantly affect postoperative outcomes. However, the Urethral plate length was not significant. We tried to find cutoff values for each factor for more refinement; we found that a GMS score $>6$ is associated with a higher risk for complication following TIP repair. Also, Glans width $\geq 14 \mathrm{~mm}$ and penoscrotal length $\geq 5 \mathrm{~cm}$ had lower complication rates following TIP repair. However, we could not find cutoff value for the rest of the parameters. We recommend that more efforts be made to refine a standard prognostic model for better evaluation.

One of the most critical study limitations was that the surgeries were performed by multiple surgeons in addition to the wide bracket of age included in the study. Also the small sample size might have affected the results.

\section{Conclusion}

GMS score and penile parameters are good predictors and complete each other in preoperative assessment for hypospadias patients. Patients with a high GMS score (above 6) have a higher risk of complication and patients with a Glans width of $14 \mathrm{~mm}$ or more and a penoscrotal length of $5 \mathrm{~cm}$ or more are associated with less risk of complication.

\section{Abbreviations}

MAGPI: Meatal advancement and glanuloplasty; ROC: Receiver operator characteristic curve; TIP: Tubularized incised plate; PL: Penile length; UPL: Urethral plate length; PSL: Penoscrotal length; GW: Glans width.

\section{Acknowledgements}

No acknowledgements.

\section{Authors' contributions}

Design of work by Ash and WA, analysis of data by MA and WG, collection of data by $\mathrm{AA}$ and $\mathrm{ASho}$, revision of the work by HM and ME, approval of the submitted version by HB and MEi. All authors have read and approved the manuscript and approved its publication with the sent form.

Funding

No funds.

\section{Availability of data and materials}

The datasets used and/or analyzed during the current study are available from the corresponding author on reasonable request.

\section{Declarations}

\section{Ethics approval and consent to participate}

Approved Department Council of Kasr Al Ainy Hospital Cairo University with no available ethical number as it does not need a number, because it is not a clinical trial. Date of ethics committee approval is 12th of January 2017. Informed written consent from parents/guardians of patients under 16 years old was obtained.

\section{Consent for publication}

Written informed consent for the publication of this manuscript and images was obtained from the participants' parents or legal guardians in the case of children under 16.

\section{Competing interests}

Dr Mohamed El Ghoneimy is a co-author of this study and editorial board member of the journal. He declares a competing interest for this submission. He has not handled this manuscript. The rest of the authors have no conflict of interest to declare.

Received: 12 August 2020 Accepted: 12 June 2021

Published online: 22 July 2021

\section{References}

1. Arlen AM, Kirsch AJ, Leong T, Broecker BH, Smith EA, Elmore JM (2015) Further analysis of the Glans-Urethral Meatus-Shaft (GMS) hypospadias score: correlation with postoperative complications. Ped Urol 11:71

2. Ságodi L, Kiss A, Kiss-Tóth E, Barkai L (2014) Prevalence and possible causes of hypospadias. Orv Hetil 155:978-985

3. Bhat A (2008) General considerations in hypospadias surgery. Indian J Urol IJU J Urol Soc India 24(2):188-194

4. Merriman LS, Arlen AM, Broecker BH, Smith EA, Kirsch AJ, Elmore JM (2013) The GMS hypospadias score: assessment of inter-observer reliability and correlation with postoperative complications. J Pediatric Urol 6:707-712

5. Sarhan O, Saad M, Helmy T, Hafez A (2009) Effect of suturin g technique and urethral plate characteristics on complication rate following hypospadias repair: a prospective randomized study. J Urol 182(2):682-685

6. Weber DM, Schönbucher VB, Landolt MA, Gobet R (2008) The Pediatric penile perception score: an instrument for patient self-assessment and surgeon evaluation after hypospadias repair. J Urol 180:1080-1084

7. Holland AJA, Smith GHH, Ross Fl, Cass DT (2001) HOSE: an objective scoring system for evaluating the results of hypospadias surgery. BJU Int 88:25-28

8. van der Toorn F, de Jong TP, de Gier RP, Callewaert PR, van der Horst EH, Steffens MG, van Busschbach JJ (2013) Introducing the HOPE (Hypospadias Objective Penile Evaluation)-score: a validation study of an objective scoring system for evaluating cosmetic appearance in hypospadias patients. J Ped Urol 6:1006-1016

9. Snodgrass W, Bush N, Cost N (2010) Tubularized incised plate hypospadias repair for distal hypospadias. J Ped Urol 6(4):408-413

10. Bush NC, Holzer M, Zhang S, Snodgrass W (2013) Age does not impact risk for urethroplasty complications after tubularized incised plate repair of hypospadias in prepubertal boys. J Ped Urol 9(3):252-256 
11. Bush NC, Villanueva C, Snodgrass W (2015) Glans size is an independent risk factor for urethroplasty complications after hypospadias repair. J Pediatr Urol 11(355):e1-5

12. Huang J, Garcia-Roig M, Geng Z, Cerwinka W, Kirsch A, Scherz A, Smith E, Elmore J. Glans width and urethral plate width: correlation with postoperative complications in hypospadias. Abstract presented at the 64th annual meeting of the society of pediatric urology, San Diego, California, May 6-8, 2016.

13. Faasse MA, Johnson EK, Bowen DK, Lindgren BW, Maizels M, Marcus CR, Yerkes EB (2016) Is glans penis width a risk factor for complications after hypospadias repair? J Ped Urol 12(4):202-210

14. Netto JM, Ferrarez CE, Schindler Leal AA, Tucci S Jr, Gomes CA, Barroso U Jr (2013) Hormone therapy in hypospadias surgery: a systematic review. J Ped Urol 9:971-979
15. Da Silva EA, Lobountchenko T, Marun MN, Rondon A, Damiao R (2014) Role of penile biometric characteristics on surgical outcome of hypospadias repair. Ped Surg Int 30:339-344

\section{Publisher's Note}

Springer Nature remains neutral with regard to jurisdictional claims in published maps and institutional affiliations.

\section{Submit your manuscript to a SpringerOpen ${ }^{\circ}$ journal and benefit from:}

- Convenient online submission

- Rigorous peer review

- Open access: articles freely available online

- High visibility within the field

- Retaining the copyright to your article

Submit your next manuscript at $\boldsymbol{\nabla}$ springeropen.com 